\title{
LANDSCAPE AS A CONCEPTUAL SPACE FOR ARCHITECTURE: SHIFTING THEORIES AND CRITICAL PRACTICES
}

CROSS-DISCIPLINARY STUDIES

MICHELLE LABOY

Alvar Aalto, Town Hall, Säynatsälo, Finland, 1951.

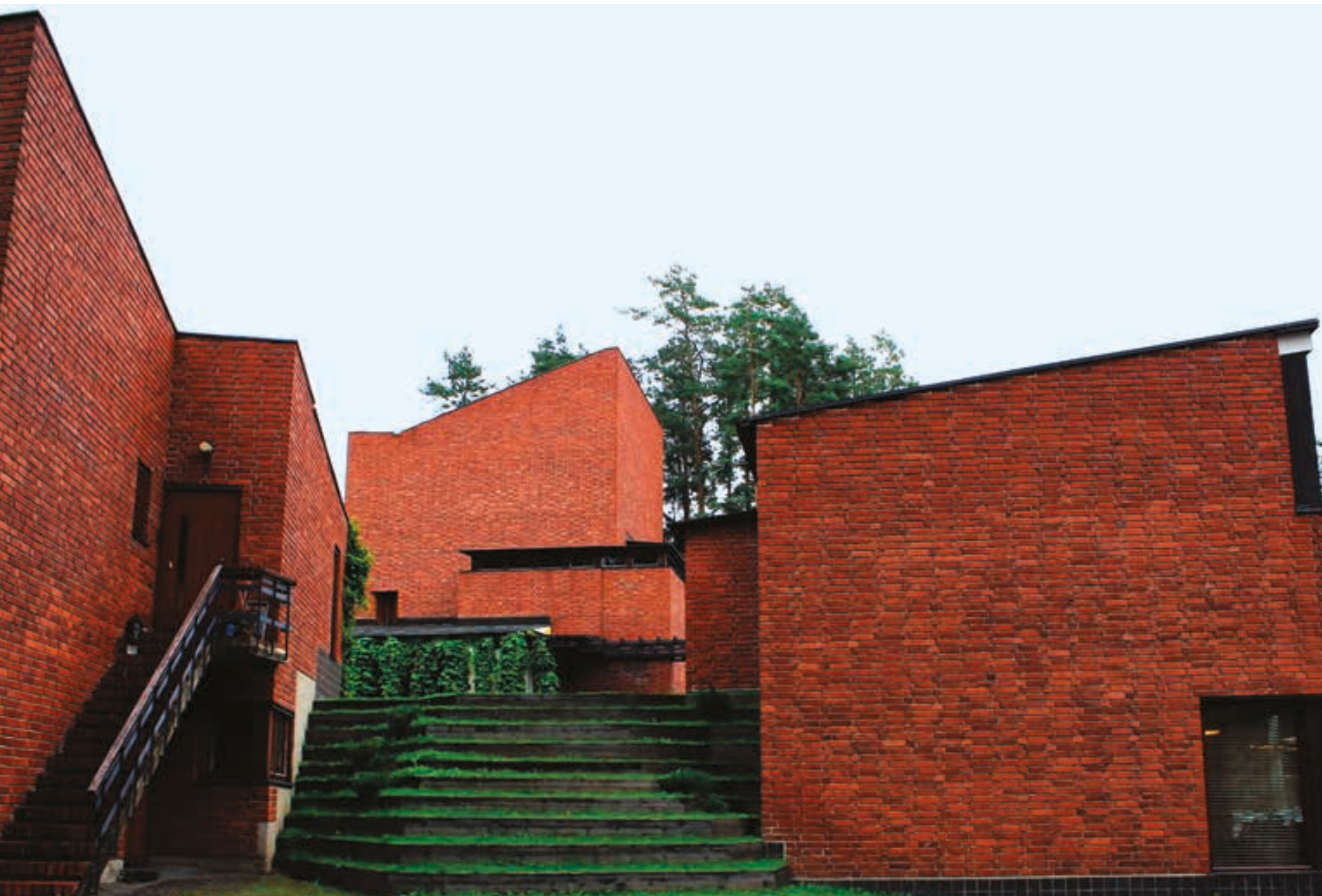


ABSTRACT - Architecture constantly negotiates the ideal and the real. These two conditions, being a reflection of cultural values and practices, change over time. I suggest that what remains constant to architecture are the lasting spatial and formal qualities that engage in constructing the physical and cultural landscape: how it channels natural light and air, how its permanent structures organize space, frame and supports life, shelter, protect and comfort. There are the qualities that make architecture endure and adapt to a changing cultural and natural environment. The placement of architecture in the real world often seems contaminated by a multiplicity of socio-economic structures and processes, but its situation in the world is also what provides an opportunity to engage in the making of a landscape where over time architecture finds a critical autonomy and relevance. The role of architecture in making or responding to the landscape is one of the critical questions in current debates about autonomy and contingency. In this paper, I expand on the work I presented at the ACSA conference at Syracuse University in the Fall of 2015, where I explored how the discipline of architecture has absorbed the landscape as a conceptual space, to "theorize critical means of engagement with the formal, spatial and performance qualities of its territory, to define critical contingencies that are meaningful through space and time, and to refuse those that can keep it tied to the trivialities of a temporary situation." More specifically, my work examines how the notion of the ecological permeates the architecture discipline from the field of landscape, providing a framework for architectural discourse to theorize the relationship of the idealized and the real, to create new singular form within a situation of multiplicity.

Keywords: autonomy, contingency, ecology, landscape, theory

"The pride of architecture was to make real the fiction, because the way in which architecture was produced implied a continuity between form, as contrived in the mind, and built form in such a way that the latter became the only existing reality. The ideal world was transformed into a real work because what characterized architecture was the fact that it should be built." (Rafael Moneo) ${ }^{1}$

Recently the Fall 2015 ACSA conference invited scholars to revisit the debate on the tension between autonomy and contingency, between architecture that is an autonomous discipline and architecture that is a cultural product, citing the work of K. Michael Hays in his 1984 essay in Perspecta, titled "Critical Architecture: Between Culture and Form." 2 Hays examined what he called a critical architecture, "one resistant to the self-confirming, conciliatory operations of a dominant culture and yet irreducible to a purely formal structure disengaged from the contingencies of place and time." ${ }^{3}$ While revisiting Michael Hay's interpretation of 
architecture as autonomous form, the notion of an idealized condition or moment occurring in a purely conceptual space". I could not help but reflect on the nature of a conceptual space in itself. I asked: "Can architecture discourse conceive of such a space where the built form can be generated on purely internal logics?"

I argue that the closest the discipline of architecture has been to creating this presumably vacuous conceptual space has been the times when in search for disciplinary autonomy the discourse centered on the creation of typological forms, codified in handbooks and manuals of the nineteenth century. Architecture typology was preoccupied originally with elemental and primitive forms, tied to history and meaning which Rafael Moneo identifies with the theories of Quatremere de Quincy's concept of "type," and later to rules of composition or disposition of architectural elements, identified as Durand's concept of genre in the XVIII century. ${ }^{4}$ Moneo makes a clear case for how the notion of type in architecture, contrary to the common perception of abstract geometry, was a formal structure "intimately connected with reality-with a vast hierarchy of concerns running from social activity to building construction."

\section{A CONCEPTUAL SPACE FOR ARCHITECTURE: LANDSCAPE AS THE SPACE OF THE IMAGINATION}

Typology as a theory seeking autonomous form was ultimately contingent on social needs (program) and historical precedent. Yet what made it appear autonomous was that architecture was preconceived in a "purely conceptual space" where only form and the composition of architectural elements mattered, and that was largely devoided of site contingencies or theories of urbanism. Thus as a theory it had little power or desire to engage with the city or the landscape in any other way than visual. As a result, the formulation of these rules and categories of form had the unintended consequence of creating a mechanical repetition of formal strategies, the emergence of style as a source of differentiation, and thus the loss of criticality and singularity that a quest for autonomy can ultimately be justified on. Typological or compositional rules in architecture have always allowed formal accommodations to site geometry, but in any form of objectification of architecture is easy to neglect the critical engagement with the space of the landscape. In the nineteenth century, an internal crisis in architecture resulted from what Manfredo Tafuri described as the increasing primacy of formal invention (perhaps the goal of autonomy) and the simultaneous repetition of those formal inventions to a point of obsession, which generated an urban condition characterized by the accumulation of fragments that attested to how useless was the effort to invent them. ${ }^{5}$

Critical architecture theory has had to engage with what Manfredo Tafuri defined as "urban ideology," a conceptualization of the landscape: the 
urban, the rural and the in-between. Since that moment of internal crisis in architectural theory, the discipline had to engage, whether explicitly or implicitly, with the landscape as a "purely conceptual space" for architecture. Beyond the modernist critique of "type" based on form and language, much of architecture discourse in the last century has been engaged in this dialectic between autonomous architectural objects, and the space of the city, or the urban condition. This dialectic expands the formal investigation "between the role of the architectonic object and that of urban organization.".6 That is not to say that architecture engaged in urban ideology has only existed as contingent, what Hays would call an "instrument of culture" responsive to, or contaminated by the socioeconomic, political and technological processes by which it is generated. The argument made in this paper is that rather than purely a reflection of the processes that make the city, a critical architecture has emerged out of the abstraction of the landscape as a conceptual space, allowing ideas that range from the notion of region to the science of ecology to provide a new theoretical lens for architecture to observe, select, heighten and transform aspects of its situation, and to critically engage in proposing new formal, spatial and performance agendas for built form.

It is important to differentiate site, which can be naturally conflated, with landscape. Landscape as a conceptual space, has always been more abstract and therefore broadly aligned with the idealized. Whereas site, as a political or physical limit, has always been a found condition, connected to reality, and it can be more commonly tied to the immediate social, political, economic and technological conditions. A critical difference is that landscape theory has given architecture new frameworks to select and edit attributes of its site or region, and to create a more meaningful dialogue with the broader cultural construct of landscape-as an evolving idealized space. This was only possible with the emergence in the late nineteenth century of a new disciplinary autonomy for landscape theory. This discourse in landscape transformed the idea of landscape itself from what Elizabeth Meyer described as a passive setting (or ground) for architecture - and James Corner characterized as a passive product of culture-into an active and strategic agent of culture. ${ }^{7}$ Furthermore, it was the engagement of critical landscape theory with the field of ecology and the "aesthetics of sustainability," that resulted in an evolution of the concept of landscape from its origins in painting into a field of dynamic systems. Examining this evolution in landscape theory, and the corresponding theories and practices emerging in architecture as a response, elucidates how ecological concepts of scale, site and systems have been translated into a new conceptual space or framework for formal investigation in architecture.

Recently, landscape has dominated the discourse of ecological design and urbanism, inviting introspection in the field of architecture, as it seeks 
to redefines its role and relationship to the landscape. Over the last ten years the theoretical discourse of architecture has shown increased activity and interest surrounding to notions of site, region and landscapeterms that are likely borrowed from landscape theory. The publication of the book Site Matters in 2005, edited by Andrea Kahn and Carol Burns, was presented as the first significant effort at formalizing a theory for site as a conceptual structure in architecture, a subject in which the editors stated there was scanty literature. ${ }^{8}$ Ten years later, we can no longer say that site occupies a marginal place in architecture theory. The theory of landscape urbanism, compiled in a volume edited by the architect Charles Waldheim, brings together multiple disciplines in conceptualizing urbanism as landscape, and describing new forms of collaboration, what James Corner has referred to as hybrid forms of practice. ${ }^{9}$ These have been followed by numerous publications, such as Design Ecologies, where ecological thinking is central to design in ways that are less concerned with objects or space, and more with performance and dynamics. ${ }^{10}$ This shift in attention has been driven by an increased attention to the environmental crisis, the importance of the field of sustainability, and the search for solutions in ecological planning to replace the version of twentieth century planning that had been discredited by critical theory or challenged by new forms of growth that resist older models and solutions based on the morphological categorization of urban fabric.

However, it is important to recognize that, although more visible in the discourse now, the exchange of ideas between landscape and architecture theory is not a recent development, and in fact has been a part of critical architecture practice for a long time. What we can see in a brief historical survey is that the notion of landscape has provided a conceptual space for architecture for over a century. In this conceptual space the discipline of architecture has engaged with theories of place, regional identity, nature and lately the ecological. Through the following sections this paper examines some of the ideas exchanged between the fields of architecture and landscape theory at critical moments in history. The objective is to understand how the cultural and collective imagination of a territory - whether it is imagined as a natural condition or a constructed ecology - defines a conceptual space for critical architecture to be practiced.

\section{ARCHITECTURE AS OBJECT OF THE NATURALIST CITY}

"Urban naturalism, the imposition of the Picturesque on the city and its architecture, and the emphasis on landscape in artistic ideology, all served to negate the now manifest dichotomy between urban and rural reality, to pretend that there was no gap between the valorization of nature and the valorization of the city as a machine for producing new forms of economic accumulation." (Manfredo Tafuri) ${ }^{11}$ 
Before the twentieth century, early theories of landscape, with its origins in painting, transformed observations of reality through subjective experience and imagination, into scenery where not only the human subject and the architecture object, but also the city, were minimized against the dominance of an immense and dominant Nature. Architectural theorist Manfredo Tafuri critiqued these naturalist concepts of the city, as they proved to conveniently neglect the distinctions between the natural and the urban, thus questioning the morality of comparing the city to a natural object and proposing that in urban naturalism architects took an ahistorical position "freed from any structural considerations." ${ }^{12} \mathrm{His}$ argument suggests that naturalism allowed architecture a destructive autonomy by creating a conceptual space where the landscape of the city was a natural or given condition, and therefore devoided of many political and moral dimensions, allowing architecture to be produced without addressing the conditions of economic and social inequality, and environmental degradation involved in its making. This coincides with the rise of typological study of architecture, a search for formal autonomy that exploited the picturesque notion of idealized architecture objects placed in an imaged and heightened natural condition. Tafuri suggested that the lack of a clear urban ideology is what generated the "struggle between city and architecture." How was this idea supported by landscape theory? Tafuri claims that this selectivity of context or a site-less conceptual space developed for architecture was similar to the landscape painter that selects the parts of Nature that should be heightened. "As a human creation, the city tends toward a natural condition, in the same way that the landscape, through the critical selection made by the painter, must necessarily bear the stamp of a social morality." ${ }^{13}$

We can find similar critical responses and moral questions in earlier landscape theory. The idealized landscape types of the picturesque and pastoral in earlier landscape theory generated what Elizabeth Meyer describes as critical and alternative views built around the notion of site, which emerged in the late nineteenth and early twentieth century: suggesting the observation of the site's precise conditions, the selective representation of its features, and its editing to improves found conditions. ${ }^{14}$ Specifically, Meyer explores how landscape theory questioned the morality of "transposing idealized landscape types" to a new continental, regional or local condition, referencing examples of early work in American landscape architecture. These alternative theories prioritized scale and local or regional ecology rather than the imported aesthetic principles of idealized typologies.

A parallel but rather abstract alternative emerged in architecture in the early twentieth century when the discipline rejected typology and engaged in an examination of space. However abstract that alternative may have been, the notion of continuous space is where architecture first engaged with the landscape as part of its internal logic, albeit 
sometimes still in purely visual terms. Typologically derived architecture often borrowed the imaginary and distant landscape as passive ground for autonomous forms that could undermine the contingencies of its real situation. But the emergence of critical landscape theory that addressed local ecology, and the evolution of disciplinary tools in the last century that facilitated measuring, representation, and analysis of the landscape, have made landscape systems more legible in their multiplicity and complexity, allowing the evolution of the conceptual basis of landscape from the pictorial to the ecological. The city as a natural condition is no longer an excuse to avoid political and moral questions. It is in fact the acknowledgement of the most important moral questions of our time, the expansion of the effect of human action in the natural environment, the degradation of the rural landscape, and the understanding that cities have become unique constructed ecologies with their own logic and processes. In Elizabeth Meyer words: "Landscape architectural theory is uniquely positioned to contain, inscribe, embed, and express within its spaces and forms a culture's complex and contradictory attitudes about the natural world." 15

The conceptualization of mechanisms and organizing principles of ecosystems is fostering a new collective imagination of what comprises the landscape. Through this lens, in the context of urbanism, the conceptual space of the city is a dynamic system in which all parts, buildings and natural systems, are designed and constructed as interconnected, and interdependent. This changing paradigm of landscape has profoundly shifted the conceptual ground on which architecture is built. Therefore the urban landscape is not a vacuous or pure conceptual space where architecture exists in isolation. Instead, much like the discipline of landscape ecology has transformed design through systems thinking, architecture in the urban landscape no longer designs autonomous objects in sites, but instead defines different conceptual boundaries to define ecosystems at different scales. The autonomy of the architecture object emerges from occupying a unique niche in the landscape ecology.

\section{ARCHITECTURE AS LANDSCAPE}

Beyond the abstract notions of continuous space, new interpretations of modernism's most significant work reconsider the notion of landscape in architecture. Critical reinterpretations emerged of a modern architecture that was conceived as a constructed landscape, rejecting the notion of landscape as purely external condition bounded to nature. Caroline Constant's new interpretation of Mies van der Rohe's German pavilion in Barcelona (1929) suggests that the pavilion was conceived as a landscape by rejecting historical references to the pavilion of the English landscape garden, undermining its status as an object, overcoming the 
static quality of the picturesque object terminating a vista, and denying any symbolic references to nature. ${ }^{16} \mathrm{~A}$ recent exhibition of Le Corbusier's work at the Museum of Modern Art in New York, revisited his work through the lens of landscape, analyzing his drawings and his work both as an instrument to view the landscape and as constructed landscapes in themselves. For example, in the Villa Savoye (1929-31) Le Corbusier explored architecture as both framed view that borrowed the distant landscape, and as constructed landscape through the device of the architectural promenade that culminated in the roof terrace.

Operating within the historic or traditional city, modernism's dialogue with the landscape was less about constructing a landscape and more about resisting the existing structures of the city. According to K. Michael Hays, Mies' work in urban proposals for Alexanderplatz (1928) engaged in a form of critical resistance, avoiding any formal conciliation with the historical urban context. ${ }^{17}$ But instead of de-objectifying architecture, as Mies later achieved in the Barcelona Pavillion, his urban proposals relied on a language of repetitive objects, creating resistance and difference with their context. The contradiction of this form of critical architecture through resistance to the traditional city, the site where Moneo has placed the Modern movement's failure, is that what he called the industrial prototype returned architecture to an archetypal instrument that could be conceived and readapted without alteration on any site. ${ }^{18}$ In doing so, the prototypical object relegates the urban landscape once again as a passive ground that receives architecture. This contradicts the anti-formalist position of Mies van der Rohe, and other modernists who rejected the nineteenth century formal manipulations of architecture types to conform to existing configurations of urban space, but in its place these proposals did not always succeed in engaging with the urban landscape in meaningful ways. In the "undifferentiated sameness" (a loss of singularity) these forms not only "abstain from any dialogue with the physical particularities of their contexts" but also "deny the possibility of attaching significance to the placement or arrangement of the forms." ${ }^{19}$ Ultimately, the interpretation of architecture as a form of resistance is only possible in the context of its making, or in a historical retrospect. Once that form becomes part of a real condition, similar to any typological condition, its repetition and export is no longer critical. The logical conclusion was, according to Rafael Moneo, that "such an attitude toward mass production was in clear contradiction to the Modern Movement's own preoccupation with the unique spatial object." ${ }^{20}$ In the context of urbanism, the modern movement too often lost connection with the particularities of region, place and site that were critical to the landscape discipline. As Elizabeth Meyer said, the "abstraction, objecthood, uniqueness and universality that characterized modern art and design" marginalized landscape architecture's focus on matters of site. ${ }^{21}$

While it is true that abstraction of modernism was challenged by site concerns, as Meyer suggested, some manifestations of modernism 
did engage with the conceptual space of the regional landscape, as a reaction to that same abstraction, and as a form of criticism in architecture. This development paralleled what Elizabeth Meyer described happening in landscape theory: the reaction to the transposition of idealized types and the formulation of concepts tied to place. ${ }^{22}$ Reflecting the discourse in the landscape field, we begin to see distinctions between landscape (the generalized) and site (the specific) emerging in the conceptual space of architecture. Frank Lloyd Wright appropriated the landscape of the Midwestern prairie as a conceptual space for a new language, which generalized and systematized formal relationships to solar orientation, climate, views, spatial continuity, scale and hierarchy in the production of architecture that was specific to the northern American landscape, but that was flexible enough to engage with multiplicity and specificity by being site-inflected. This language emerged from the abstraction of formal qualities of a region. Region as a concept had been prevalent in the discourse of landscape theory. The translation of region to architecture was more formal than ecological, but it provided a renewed autonomy to the discipline so that the boundaries of the region were reinterpreted as cultural in many different sites. Although his urban proposal of Broadacre City also failed to address the traditional city, and completely rejected it, its organizational principles were, for better or worse, based on the adaptation of a uniquely regional American landscape, and the desire, although naïve, to connect people to nature in daily life.

Similarly, the work of Alvar Aalto adapted modern functionalism to the regional landscape of Finland through formal, material and tectonic expression of an architecture that was conceived as landscape. The Säynätsalo Town Hall (1949-52) by Alvar and Elissa Aalto is an example of this approach. This project has been described as inspired by the landscape of the Italian hilltop town center. The Aaltos situated and generated a new language for modern architecture by importing a traditional image of the civic landscape as an architectural typology, transforming it through the material and topological integration of the building with the Finnish landscape. (Fig. 1) Combining qualities of its natural and cultural landscape: the mediation of light through structure, the vegetated surface and the topographical form of the building, were engaged in, transforming a single architectural intervention into an idealized landscape. Although the building emerges from the abstraction and importation of the image of a foreign landscape, the spatial, formal and material operations engaged with the real site and the Finnish landscape in meaningful and humanizing ways . Similarly, Aalto's urban proposals followed the ideas of standardization of early modernism, humanized and adapted to the cultural and natural landscape of Finland. He said of standardization: "nature herself is the best standardization committee in the world, but in nature, standardization is almost exclusively applied to the smallest possible unit, the cell. This results in millions of 


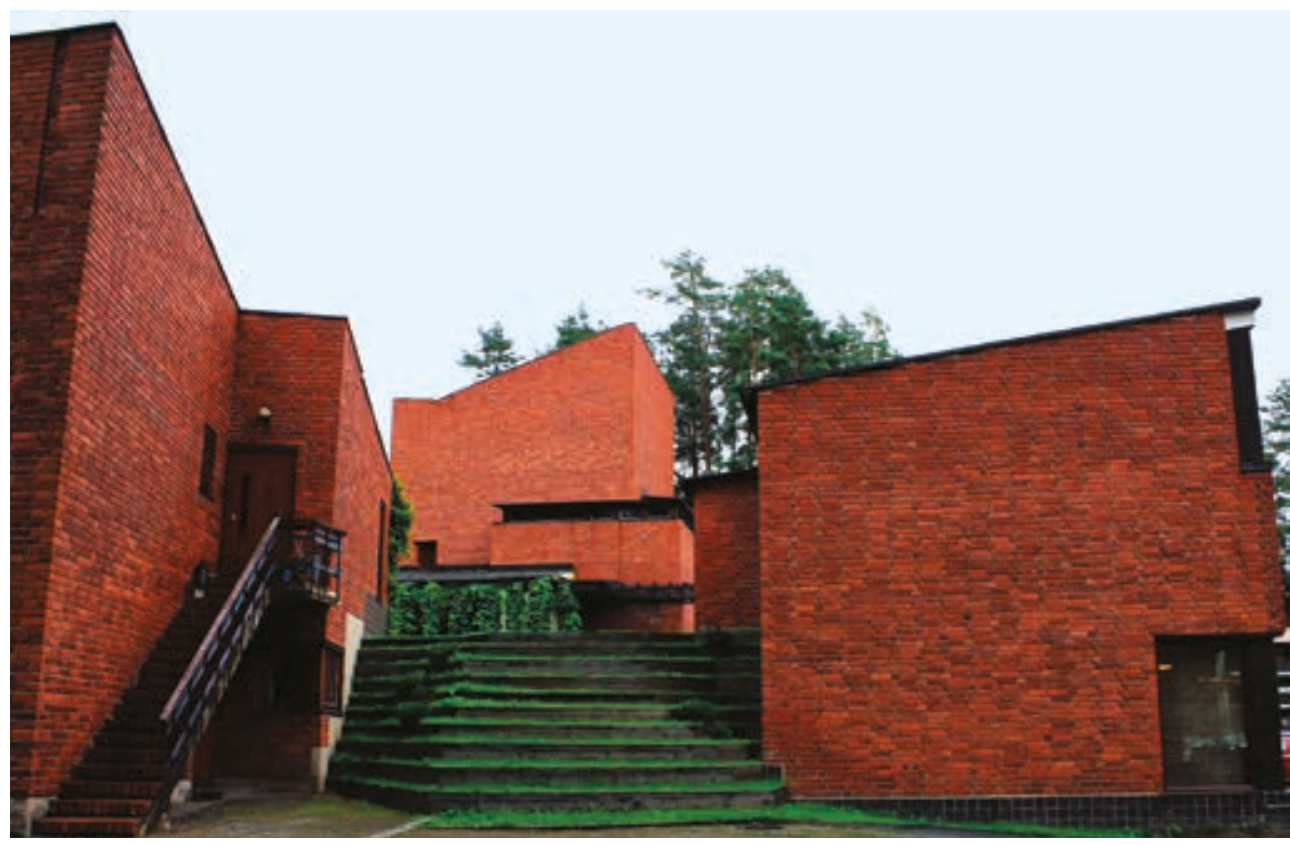

Figure 1. Alvar Aalto, Town Hall, Säynatsälo, Finland, 1951. The building creates a terraced landscape the opens the courtyard of the town hall along one corner to spill into the surrounding woodland.

flexible combinations that never become schematic. It results in unlimited riches and perpetual variation in organically grown forms. We must follow the same path in architectural standardization." ${ }^{23}$ In that context, the objective of prototypes was not their endless repetition, but the infinite variation that humanized and contextualized them to their particular landscape. Eeva-Liisa Pelkonen argues that Aalto had an ecological view of architecture and planning, even though he did not use the term, because his thinking was "focused on the interactions between organisms and their environment." ${ }^{24}$ Alto's schemes, including his theoretical city called "An American Town in Finland," developed while he was teaching at MIT, explored how the standardization of prefabricated housing could be recombined and adapted to site specificities and landscape conditions.

\section{ARCHITECTURE OF ECOLOGICAL PERFORMANCE}

The evolution from landscape as natural condition, against which the technical object sits, to architecture as a constructed landscape, has given way to a recent view of landscape as ecology. The metrics of ecological landscape are defined by performance, process and relationships of its parts. The contemporary discourse of landscape and urbanism is less concerned with visual or formal qualities, but with the ecological performance of form. According to the landscape architect and theorist James Corner, this new view of landscape invites a reinterpretation of the most significant spaces of the nineteenth century 
landscapes through an ecological lens. For example, the value of Olmsted's landscapes today, are less representational or aesthetic, but more on their role in the city as "ecological vessels and paths". ${ }^{25}$ The ecological lens of the landscape constitutes a profound shift in urban ideology. In the current state of environmental crisis, engaging landscape ecology as a conceptual space for architectural production is critical to make the discipline relevant to contemporary life. Architecture can engage the current agenda of the landscape discipline in constructing or restoring designed ecologies, by building on the notions of city as nature and architecture as landscape. The "disciplinary contamination" Elizabeth Meyer has described as "the intermingling of aesthetic discourses and conventions" with knowledge from other disciplines, such as geology and ecology, enriched the vocabulary of landscape architecture. ${ }^{26}$ Similarly, the disciplinary contamination from landscape and ecology is proving enriching to architecture. A critical contemporary practice understands the performance of architectural form as an experiential and environmental device integral to landscape ecologies.

The concepts and aesthetics of sustainability and ecological performance, long a part of the conceptual territory of landscape theory, have permeated architecture practice. For a scholar interested in the dialogue between architecture and the natural environment, it seems worth studying the cultural and technical implications of concepts and intellectual frameworks, such as resilience, that are transferred from ecology to design fields. The ecologist C.S. Holling defined resilience, namely "a measure of the persistence of systems and of their ability to absorb change and disturbance and still maintain the same relationships" in contrast to stability, which we have traditionally associated with the permanence of architecture. ${ }^{27}$ Conceiving of architecture as a component of dynamic systems that is integrated to landscape ecologies in productive relationships is a dramatic conceptual shift for architecture practice. It is hard to think of architecture as object in this context. Systems thinking implies that architecture is only a boundary describing a system of systems, and that when we expand the boundary to include its site, or territory, those systems can be understood as connected to much larger ecological, cultural and infrastructural systems. The term resilience has been in use in landscape and infrastructure systems for some time, but it is still new in the field of architecture, often used loosely, and without consensus in its definition and application to buildings. However, its value as a metaphor has been suggested as fostering the ability to rethink institutional structures that encourage slow restructuring, pattern behavior and preservation of current practices. ${ }^{28}$

In contrast, sustainability in design, its metrics and aesthetics, has been explored for quite some time. But sustainability is focused on optimization, often pursuing notions of self-sufficiency. In that conceptual framework, the building can be conceived as an island, or its performance measured 
in terms of degrees of independence (e.g. net-zero, off-the-grid). A shift to true ecological thinking focuses on relationships. Most importantly, it recognizes that any act of building transforms and reconstructs a large territory, will affect or connect to infrastructural networks far beyond what we usually comprehend, and to an existing ecology that is complex and diverse. Therefore it demands that the landscape and the architecture are not reductive, and instead be thought of as integral to each other, in terms of systems and not objects. Form is generative of performance, and although conceptual frameworks and a degree of abstraction from the real world are still needed to comprehend those complex systems and relationships, this generates a different kind of autonomy. Hay's description of a vacuous conceptual space for the autonomous object has been transformed into a conceptual framework to explain and reimagine highly complex and contingent systems.

New forms of critical practice have emerged in the last few decades, by adopting the landscape field's ecological thinking into the conceptual space of architecture. Some notable collaborations between architecture and landscape practices are resulting in an ecological approach to urbanism that reframes architecture as an active agent of the landscape. The type of projects they develop do not fit Hay's definition of contingent architecture that is a cultural product, a reflection of socio-economic structures, or conventions of practice. These projects not only are contingent to ecological conditions, but in their effort to construct a new landscape ecology, they create ecosystems and define ecotones in the urban environment, restore relationships, provide ecosystem services and heighten the awareness of the systems that support urban life. The architecture and landscape generated from this way of thinking become singular forms, responding to climate and assertively creating new microclimates. The field of ecology is inherently about relationships, developing abstract models of representation to diagram and explain complex and contingent systems. As a conceptual space for architecture landscape ecology provides a framework to categorize, analyze, select, and engage with the contingencies and performance of systems. Frameworks of ecological performance allow architectural form to engage complexity, and to define its active role as consumer and producer of ecosystem services. Architecture in this context is not a passive object sitting on scenery, but instead must become an active agent in restoring or constructing new urban ecologies.

\section{NEW CRITICAL PRACTICES}

Two significant spaces in the urban landscape of Brooklyn: the Botanical Garden at Olmsted's nineteenth century Prospect Park and the new Brooklyn Bridge Park being built along the waterfront, provide didactic examples of this critical form of hybrid practice. Unlike much of the 
urban environment elsewhere, these two landscape spaces exist in an intensely dense and complex urban condition and are therefore clearly defined by distinct constructed ecological boundaries between the seemingly "natural" and the "built". These classifications are in themselves problematic, as an ecological view of this landscape would suggest there is nothing strictly natural about the open space, and nothing strictly unnatural about the urban fabric. The terminology has been discussed elsewhere at length, and that can be the topic of another paper. What is relevant about this distinction is that these two spaces, designed at two very different times in history, perform important ecological functions in the cultural and physical landscape of the city. Two architectural projects within these remarkable landscapes illustrate the output of practices that are deeply committed to a collaborative and integrated model of architecture and landscape, developing singular forms that are formally experimental but not self-referential, and that are generated from an understanding of the human and natural ecology of the site in ways that make those systems legible. Both projects illustrate that an ecological approach to landscape creates a conceptual space where architecture cannot be objectified or reduced to categories of autonomous or contingent.

Prospect Park is a cultural product of a unique moment in nineteenth and early twentieth century when Olmstead adapted theories of idealized pastoral landscape for the American city, to create more than purely visual compositions that were informed by the reading of the geological qualities of the glacial landscape of Brooklyn. ${ }^{29}$ Reinterpreted as an ecological space, this landscape has provided important open space for the urban population, a rich and diverse flora and fauna, and assumed an important role in the microclimate, air and water systems. Its historical and cultural significance, apart from being one of the oldest and most important urban landscape spaces in American urbanism, is that it is designed by one of the founding figures of the landscape architecture discipline. As the city of Brooklyn grew in scale and density, this landscape has achieved a new significance in contrast to the intense urban condition around it. Its relationship to the context has been reframed through a contemporary intervention in the space of the Brooklyn's Botanical Garden, a unique moment within the landscape of Prospect Park. It's highly curated landscape is a sequence that starts along the strong urban edge of Washington street's wall of buildings, transitions to a formal and ordered garden and then dissolves into a designed condition of wilderness along the Flatbush Avenue edges that blends into the dense woodlands of Prospect Park right across. Weiss Manfredi was commissioned to design a new visitor center to the Botanical Garden. Their work siting the building was sensitive to this transition from ordered to wild landscape. The chosen location created a challenge of acknowledging the presence of the building as an object on a strong urban edge, and at the same time negotiating its presence in the historic landscape. Similar to the reading 


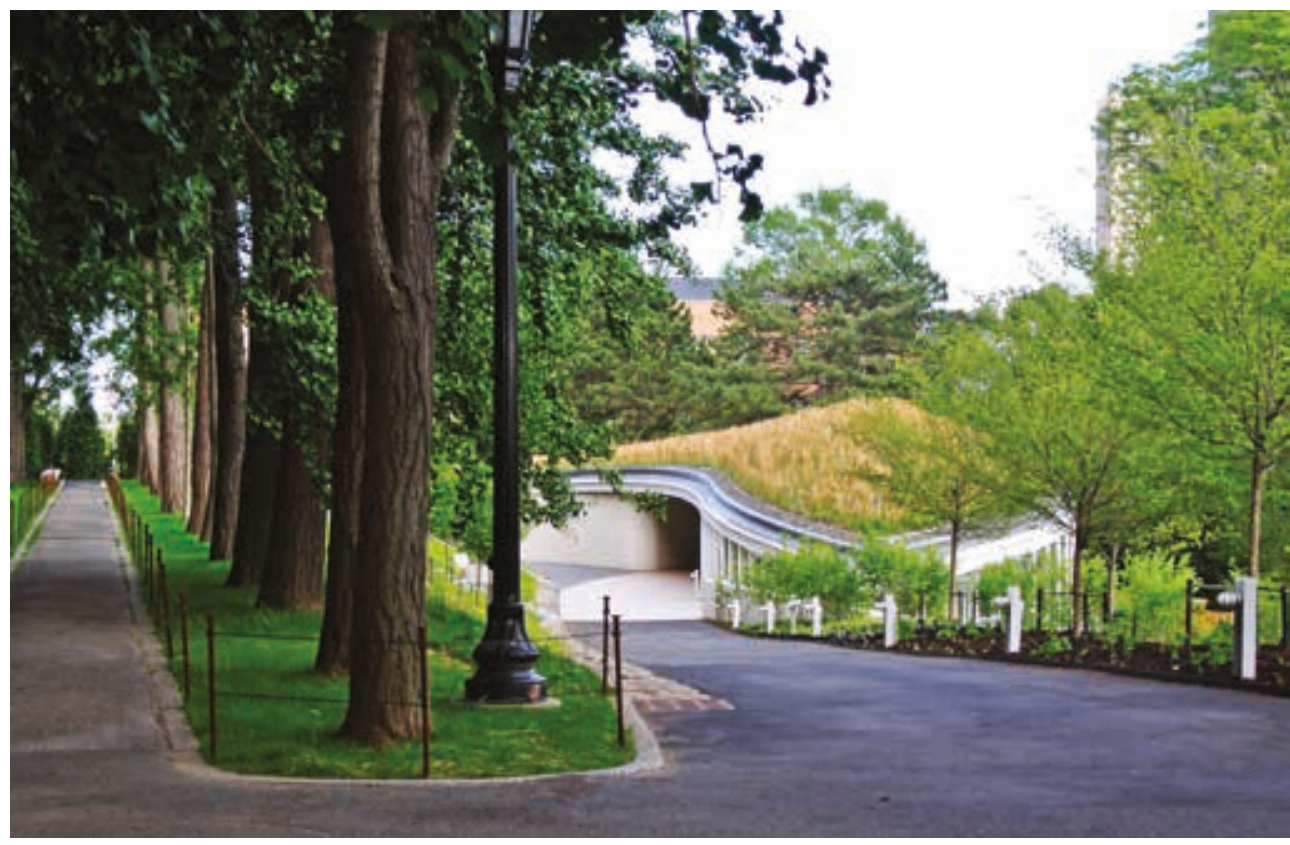

Figure 2. Weiss Manfredi (architects) with HM White (landscape architects): Brooklyn Bridge Botanic Garden, 2012. The building on the right sits parallel to the berm that separates the garden from the parking lot. The paths of the landscape cut through the volume of the building, opening on the other side to the rain gardens.

of Mies's Barcelona Pavilion, the alternative location of the building, as proposed by the architect, rejects architecture as object and as the termination of an axial vista. The architects claimed that the original location would place the building on axis with the very formal Cherry Walk, which would dominate the esplanade of trees. ${ }^{30}$ Instead, along one axis the building is a lamination onto the berm that separates the garden from the parking lot, and while on Washington Street the building creates a clear architectural edge that unravels into pavilions under layers of vegetated and louvered canopies. (Fig. 2)

The practice of Weiss Manfredi has built a body of work that is characterized by the integration of building and landscape in cultural and performative ways, always leading large teams of experts in projects were legible forms on the land reveal spatial, performance and material continuities between the realm of building and site. In this project they worked with HM White Landscape Architects to expose and make legible the role of building as ground, and the ground as built form. The landscape architects describe the building and the immediate site as a system of storm water management. This integrated system also creates a new path for the curated display of plant life and creates new surfaces for biodiversity, but in this case the building creates much of the ground for that life on its roof. (Fig. 3) As a didactic landscape, the storm water management system is the most visible way to understand the role of a constructed landscape-based landscape system that integrates building 


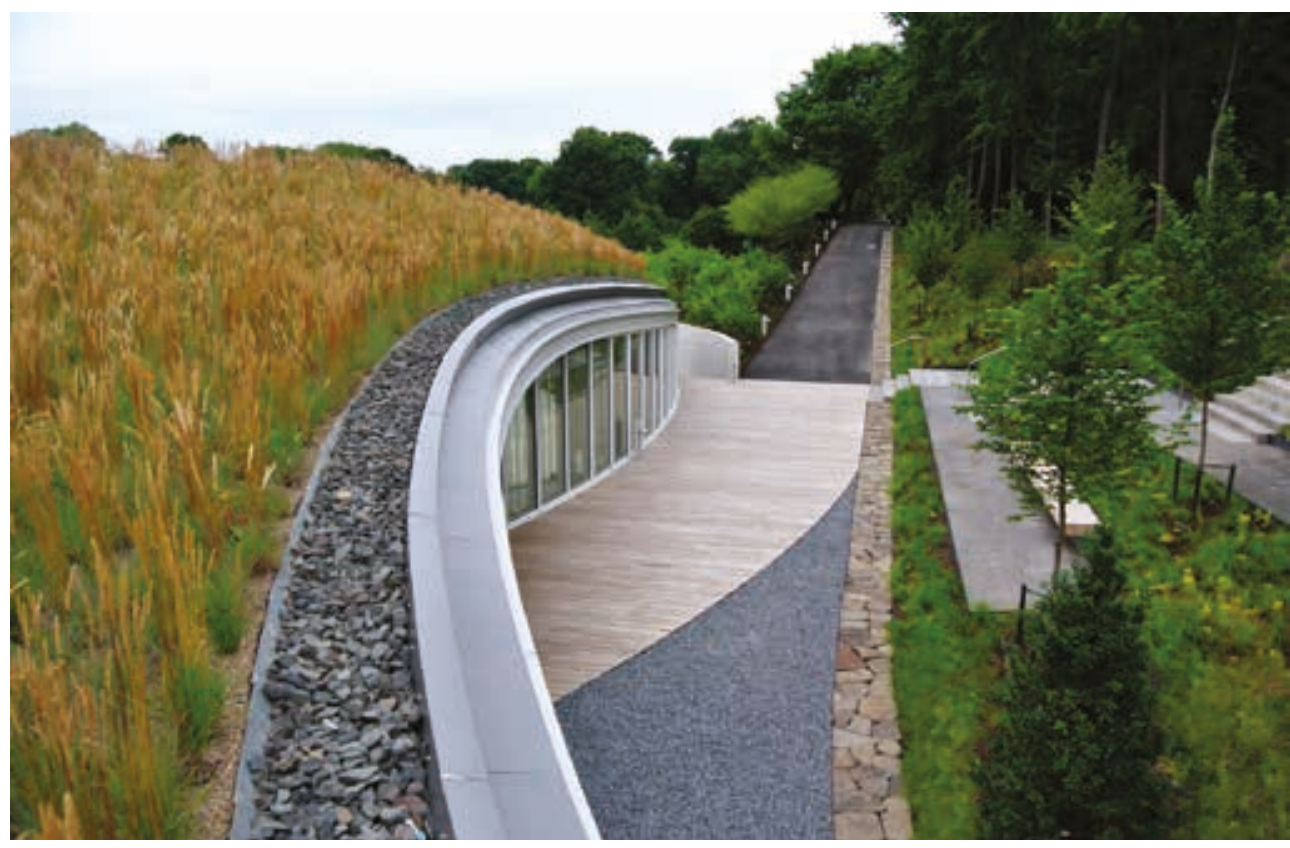

Figure 3. Weiss Manfredi (architects) with HM White (landscape architects): Brooklyn Bridge Botanic Garden, 2012. Green roof in the foreground and berm in the background.

and site. Other systems integrate building and site in less visible but equally didactic ways, such as a geothermal system that exchanges energy with the ground to heat and cool the building using local energy. The architects called the garden a "constructed natural environment," based on how the design of the landscape employed trees and berms to separate what they call an "oasis" from the neighborhood. ${ }^{31}$ Conversely, the building takes on a role of constructed landscape, by creating a new edge or strengthen the boundary between street and garden, with a built form that rather than separating and formalizing, becomes a new threshold between two landscape conditions. Similar to Le Corbusier's work at the Harvard's Carpenter Center, there is an ambiguity between building and the landscape created through the weaving of paths that make the volume less legible as object. The lamination of the organic form and the vegetated surface of the building onto the berm reinterprets its form and function as an "emergent topography and constructed landform," that creates "an inhabitable extension of the berm." ${ }^{32}$ As you walk through the plaza and cross the threshold between the two pavilions of interior space, the formal structure of the building unravels into layers of structures, canopies and paths that formalize the transition into the next episode of the garden. This is an approach to building that views architecture as an instrument for human and landscape ecologies to become legible and integrated constructs. Although as a form the building still operates within the distinctions of natural and urban, its spatial experience and performance reveals a landscape that is highly integrated and revelatory of the designed nature of the urban landscape.

Nearby, Brooklyn Bridge Park (2003-present) is a very different landscape, 
focused less on preservation or reinterpretation of a historic landscape, but instead on the ecological restoration of the coastal environment. Unlike Prospect Park, the landscape of Brooklyn Bridge Park is more legible as a construction, repurposing a cargo shipping and storage facility on the waterfront of Brooklyn. The work by landscape architects from Michael Van Valkenburgh Associates (MVVA), is quite explicit about its constructed nature, but also assertive about its ecological agenda in reusing this industrial landscape. The design of the park is redefining the edges of the piers, and reconstructing its surfaces as an open urban park space. This constructed landscape also performs important ecological functions that are intended to improve the resilience of the urban environment to storms and salt water floods, that act as an infrastructure of acoustic absorption to minimize the impact of the highway in urban life, and that provides a resilient coastal ecosystems to sustain plant and animal life within intense human activity along the waterfront. The language of the park is not picturesque or pastoral, nor does it invest in the distinctions between natural or urban. The park is a dialogue between enhanced nature and urban infrastructure.

In this project, MVVA, as the lead designer, invited the office of Maryann Thompson Architects (MTA) to design the structures within the park. The collaboration between these firms over the years has generated a significant body of work that includes public spaces in the Don River Park in Toronto, the Brooklyn Bridge Park, and currently the visitor center at the historic Walden Pond, among other projects. The architecture of the Warming Hut at Pier 6 (2012), rather than a new construction, repurposed and reinvented an industrial building from the site, transforming it into another form of landscape experience. The work of MTA is known for its integration of building and site, and the creation of unfolding spatial sequences that de-objectify architecture. The principal of the firm is trained in both architecture and landscape architecture, and has built a practice known for collaborating with notable landscape architecture firms in projects of many scales. In this project, the architects turned the building from static object into a dynamic spatial sequence by exposing the original concrete core of the building, and recladding it with a spiraling ramp that leads to a newly occupied roof terrace. (Fig. 4) No surface of the building is understood as wall or roof in the traditional sense. The ramp wrapping the building creates a thick skin constructed with reclaimed timbers from the demolished industrial structures of the park. The same timbers are used for park furniture throughout the park. The louvered skin around the ramp creates a layered reading of the object, and an experience of dappled light that resembles a woodland condition. Maryann Thompson describes the layered skin of the spiraling ramp as "mimicking the unfolding qualities of the landscape" creating a "diaphanous counterpoint" to the landforms of the park and the water. ${ }^{33}$ This architecture is engaged conceptually and materially with the reuse of an industrial landscape. The resulting sculptural form of the architecture emerges from 


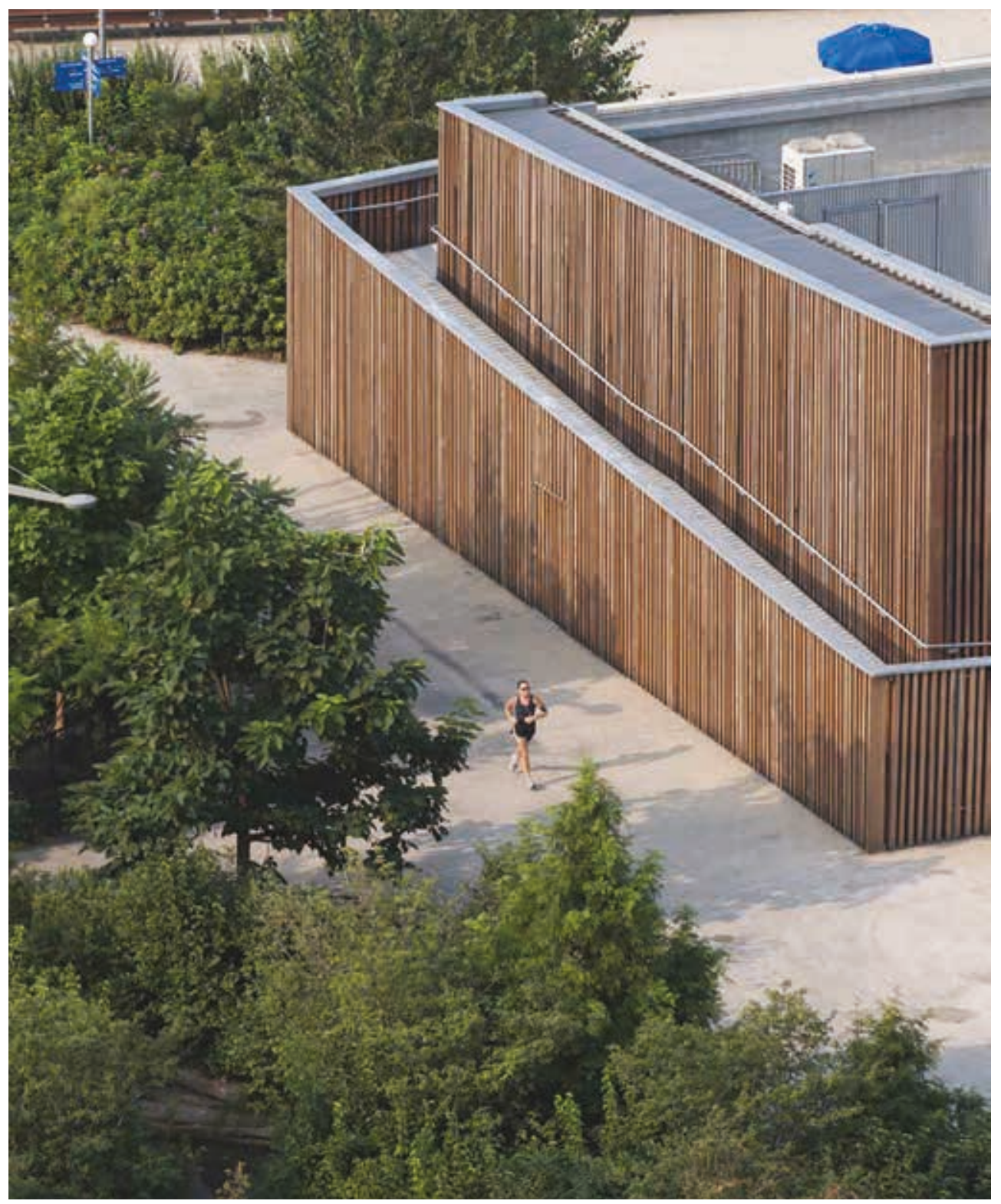

Figure 4. Maryann Thompson (architects) with Michael Van Valkenburgh Associates (landscape architects). Brooklyn Bridge Park Pier 6 Warming Hut, 2012. View from above, showing ramp leading to roof terrace.

interpreting patterns of movement on the designed landscape, pragmatic considerations of accessibility, and the material ecology of the site. (Fig. 5) The experience of the form is understood as an unfolding landscape condition that could not be generated absent the commitment to operate within the conceptual space afforded by this new landscape.

\section{Conclusions}

Evaluating the body of work of these two architecture practices shows simultaneously site specificity and a consistent repetition of themes 


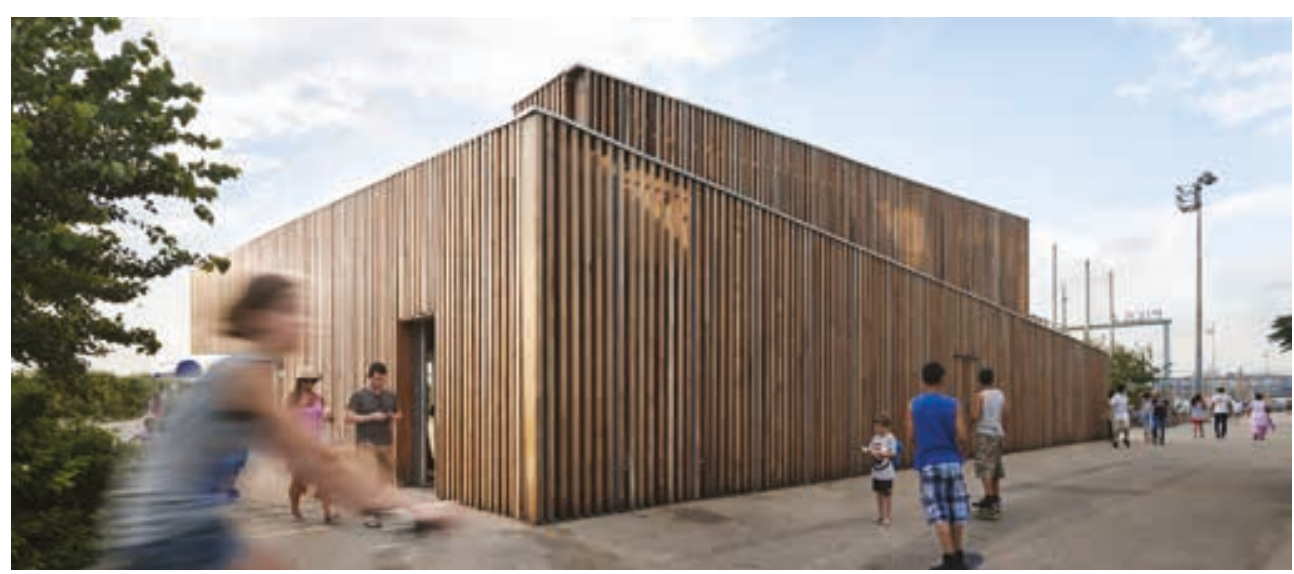

Figure 5. Maryann Thompson (architects) with Michael Van Valkenburgh Associates (landscape architects). View of Warming Hut, 2012, from the space of the Brooklyn Bridge Park Pier 6.

through language (layering, unfolding, landform, unraveling, etc). The formal language is consistent through the work, resulting from the varied inflections to site and landscape that make each building unique to its place. A deeper look shows that there is a recurring theme of ecological performance driving formal decisions, and a desire to make the landscape more legible through the instrument of architecture. In his seminal essay, K. Michael Hays described Mies' architecture program as achieving a resistant authority through the "persistent rewriting of a few themes". Although clearly the urban proposals of modernism, as represented by Mies' work discussed earlier, can be seen as problematic in their relationship to the urban landscape, Hays claimed that "a persistently rearticulated intent accumulates knowledge" and through repetition "demonstrated how architecture can resist, rather than reflect, an external cultural reality." 34

The construction of the building as a landscape has a long tradition in modernism. The use of continuous vertical and horizontal surfaces that are continuous from building to site, are increasingly common. The use of site-inflected forms, the thickening of the building edge, and the primacy of filtered light, are themes that have been rewritten in many projects by these and other practices leading in this form of hybrid practice between architecture and landscape. What transcends the formal language, is how these practices are engaged in creating new cultural forms reframing the older notions of autonomy and contingency in the discourse of architecture by considering an ecological view of form that asks critical questions about what architecture should be autonomous from-the social, economic and internal sources of disciplinary inertia driving much of the built form in the built environment-but also by being critically selective of what architecture should be contingent to, by theorizing meaningful and transformational connections with urban ecologies. 


\section{Notes}

1 José Rafael Moneo, The Solitude of Buildings: Kenzo Tange Lecture, (March 9, 1985), George Gund Hall (Cambridge MA, USA: Harvard University, Graduate School of Design, 1986).

2 K. Michael Hays, "Critical Architecture: Between Culture and Form", Perspecta 21 (1984): 14-29. doi: 10.2307/1567078.

3 Ibid.

4 Rafael Moneo, "On Typology", Oppositions: A Journal for Ideas and Criticism in Architecture 13 (1978): 22-45.

5 Manfredo Tafuri, "Toward a Critique of Architectural Ideology", in Architecture Theory since 1968, K. Michael Hays ed. (Cambridge MA, USA: The MIT Press, 1998).

6 Ibid.

7 Simon Swaffield ed., Theory in Landscape Architecture: A Reader (Philadelphia: University of Pennsylvania Press, 2002).

8 Carol Burns and Andrea Kahn, eds., Site Matters: Design Concepts, Histories, and Strategies (New York: Routledge, 2005).

9 Charles Waldheim, The Landscape Urbanism Reader (New York: Princeton Architectural Press, 2006).

10 Lisa Tilder, Beth Blostein, Design Ecologies Essays on the Nature of Design (New York: Princeton Architectural Press, 2009).

11 Manfredo Tafuri, "Toward a Critique of Architectural Ideology", 8.

12 lbid.

13 lbid., 7.

14 Elizabeth Meyer, "Site Citations", in Carol Burns and Andrea Kahn, eds., cit., 92-129.

15 Elizabeth Meyer, "Situating Modern Landscape Architecture," 1992, in Simon Swaffield, cit., 21-31.

16 Caroline Constant, The Modern Architectural Landscape (Minneapolis MN, USA: University of Minnesota Press, 2012).

17 K. Michael Hays, cit.

18 Rafael Moneo, cit.

19 K. Michael Hays, cit.

20 Rafael Moneo, cit

21 Elizabeth Meyer, "Site Citations", 94.

22 lbid., 98.

23 Alvar Aalto, "Influence of Structure and Material in Contemporary Architecture", in His Own Words (New York: Rizzoli, 1998).

24 Eeva-Liisa Pelkonen, Alvar Aalto: Architecture, Modernity, and Geopolitics (New Haven CT, USA: Yale University Press, 2009), 185.

25 Elizabeth Meyer "Situating Modern..." cit.

26 Elizabeth Meyer, "Site Citations," cit.

27 For further discussion of this topic, see Laboy, Fannon, "Learning Comprehensive Building design through a Resilience Framework", presented at the conference "Architecture and Resilience on a Human Scale" in 2015. In that paper authors quote from C.S. Holling, "Resilience and Stability of Ecological Systems," Annual Review of Ecology and Systematics 4 (January 1, 1973): 1-23. doi: 10.1146/annurev. es.04.110173.000245.

28 Rolf Pendall, Kathryn A. Foster, and Margaret Cowell, "Resilience and Regions: Building Understanding of the Metaphor", Cambridge Journal of Regions, Economy and Society 3, no. 1 (March 1, 2010): 71-84. doi: 10.1093/cjres/rsp028.

29 Elizabeth Meyer, "Site Citations," cit.

30 Clifford A. Pearson, "Groundswell," Architectural Record 200, no. 7 (July 2012): 74.

31 Michael A. Manfredi and Marion Weiss, Public Natures: Evolutionary Infrastructures, 2015.

32 Quoting the project description given by H.M. White on their online site at http:// hmwhite.com

33 Maryann Thompson, The Warming Hut at Brooklyn Bridge Park. Project Description. http://maryannthompson.com.

34 K. Michael Hays, cit. 


\section{Credits}

Figure 1. Photo: Michelle Laboy. Figure 2. Photo: Aaron Booher.

Figure 3. Photo: Aaron Booher.

Figure 4. Photo: Chuck Choi Photography.

Figure 5. Photo: Chuck Choi Photography.

Michelle Laboy is an Assistant Professor at the School of Architecture at Northeastern University. With training in architecture, urban planning and civil engineering, her career integrates teaching, research and practice at the intersection of Sustainable Architecture and Urban Landscapes. Studying the cultural, technological and theoretical context of what she calls "architectural ecology," her work explores how buildings integrate with landscapes to create sustainable and resilient ecosystems, and to actively engage people with the natural environment. She holds master degrees in Architecture and Urban Planning from the University of Michigan and a Bachelor of Science in Civil Engineering from the University of Puerto Rico. E-mail: M.Laboy@neu.edu 